\title{
Noonan Syndrome Presenting as Lymphoedema Precox
}

MD AZIZUL HAQUE, ${ }^{1}$ LAILA SHAMIMA SHARMIN,${ }^{2}$ ZAHID AMIN, $^{3}{ }^{\text {ARM SAIFUDDIN EKRAM }}{ }^{4}$

\begin{abstract}
:
Noonan Syndrome is an autosomal dominant disorder characterized by short stature, typical facial features and congenital heart defects. Other associated features are webbed neck, chest deformity, mild intellectual deficit, cryptorchidism, bleeding tendency and lymphatic dysplasia. We are reporting a 13 year old boy of Noonan syndrome presenting with lymphoedema of lower limb and genitalia.
\end{abstract}

Keyword: Noonan syndrome, Lymphoedema

\section{Introduction:}

Noonan syndrome (NS), named eponymously for the pediatric cardiologist who first described it, is an autosomal dominant disorder with a pleiomorphic phenotype. In October 1968, Jacqueline A. Noonan reported the first case with the heading "Hypertelorism With Turner Phenotype. A New Syndrome With Associated Congenital Heart Disease". ${ }^{1}$ She defined a specific group of nine patients with valvular pulmonary stenosis who, in addition, had short stature, mild mental retardation, hypertelorism, and unusual facies. In retrospect, the first case was probably described by Kobylinski in $1883 .^{2}$ These patients were previously thought to have a form of Turner syndrome, with which Noonan syndrome shares numerous clinical features. The observation that patients with Noonan syndrome have normal karyotypes was important in allowing the distinction to be made between the Turner and Noonan syndromes. After several years of controversy, this syndrome became officially recognized as "Noonan syndrome" in 1971 at the Symposium of Cardiovascular defects.

The incidence of Noonan syndrome has been estimated to be between 1 in 1000 and 1 in 2500 live births. ${ }^{3}$ Noonan Syndrome (NS) is characterized by short stature, congenital heart defects, and facial features consisting of a broad forehead, down-slanting palpebral fissures, hypertelorism, low-set posteriorly rotated ears and a high arched palate. ${ }^{4}$

1. Assistant Professor, Department of Medicine, Rajshahi Medical College

2. Assistant Professor, Department of Paediatric Nephrology, Rajshahi Medical College

3. IMO, Department of Medicine, Rajshahi Medical College Hospital

4. Professor and Head, Department of Medicine, Rajshahi Medical College

Correspondence : Dr Md Azizul Haque, Assistant Professor, Medicine, Rajshahi Medical College, E-mail: drazadbd@gmail.com
NS is clinically a very variable disorder with a number of associated features, including webbed and/or short neck, curly but not friable hair, and coagulation defects. ${ }^{5}$ Regarding the genetic aetiology of NS, missense mutations in PTPN11 have been demonstrated in $50 \%$ of patients with NS. SHP2, encoded by PTPN11, is a positive regulator of RAS/RAF/ MEK/ERK and recently, mutations were identified in three additional genes, KRAS, SOS1 and RAF1, acting within the same pathway. ${ }^{6}$

In 1994, Dutch investigator Ineke Van der Burgt proposed a clinical scoring system used for the diagnosis of Noonan syndrome. He divided the facial, cardiac, height, chest wall family history and other features into major (A) and minor (B) groups. Among the major features are typical face dysmorphology; Pulmonary valve stenosis; HOCM and/or ECG typical of NS; height $<3^{\text {rd }}$ percentile; pectus carinatum/ excavatum; first degree relative with Noonan syndrome; all three of mental retardation, cryptorchidism and lymphatic dysplasia. Among the minor features are suggestive face dysmorphology; cardiac defect other than PS or HOCM; height $<10^{\text {th }}$ percentile; first degree relative with suggestive NS; one of mental retardation, cryptorchidism and lymphatic dysplasia. Definitive NS can be diagnosed when there are 1 "A" plus one other major sign or two minor signs; 1 "B" plus two major signs or three minor signs. ${ }^{7}$ The typical facial anomalies in the NS consist of a broad forehead, hypertelorism, ptosis, down slanting palpebral fissures, micrognathia, apparently low set, posteriorly angulated ears with a thick helix, and a broad short neck. Sometimes, the facial anomalies are subtle and are suggestive of NS. ${ }^{7}$

\section{Case report:}

A 13 year old boy was admitted in Rajshahi Medical College Hospital with the complaints of swelling of right leg \& penis for 3 years. The swelling was non- pitting and there was no 
pain associated with this swelling. His parents gave no history of trauma, surgery, irradiation, joint pain or prolonged immobilization. There was no history of consanguineous marriage between the parents. He has two brothers \& sisters. All are in good health. His mile stone of development was normal. On examination, the child was cooperative and well oriented to time, place and person. There were no apparent features of mental retardation. There was non-pitting swelling of right leg extending up to penile area. Overlying skin condition and local temperature was normal. There was no lymphadenopathy. He had short stature $\left(137 \mathrm{~cm},<3^{\text {rd }}\right.$ centile in growth chart), hypertelorism, low posterior hair line, short neck, down slanting of eyes, epicanthic fold, pectus carinatum. Examination of external genitalia revealed undescended testis on right side, and penile oedema. Hernial orifices were intact. On cardiovascular system examination, there was a harsh ejection systolic murmur best heard in second left intercostal space. Investigations revealed normal CBC, normal CXR and ECG. In colour Doppler echocardiography, mild pulmonary

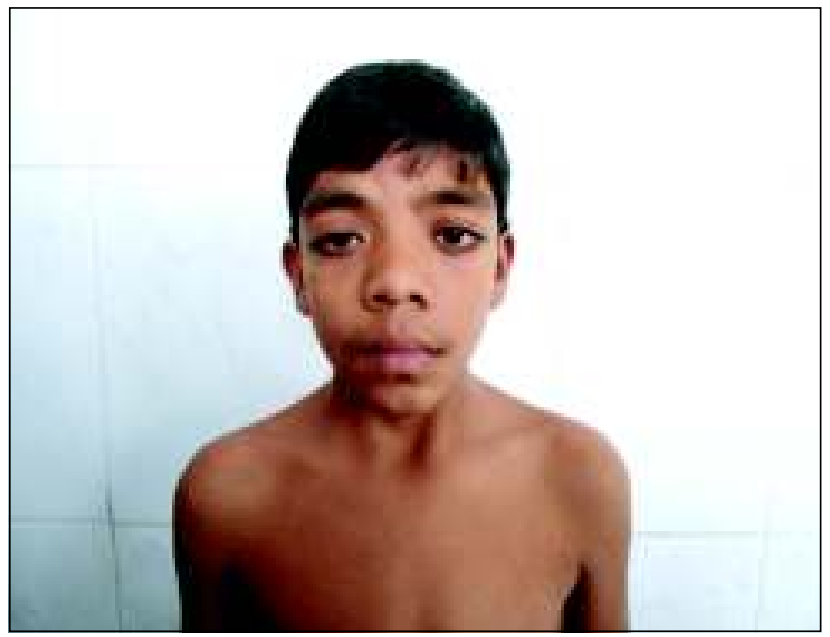

Fig.-1 and 2: showing characterstic facies

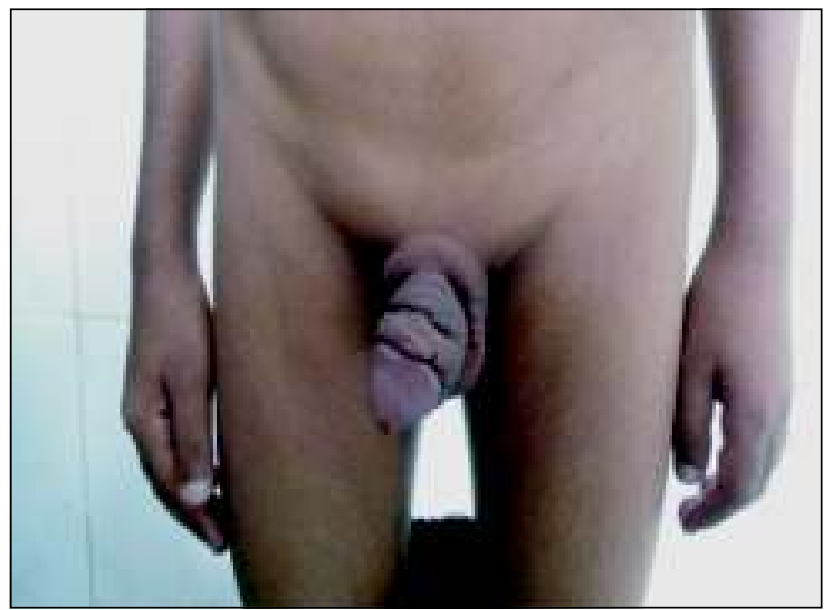

Fig.-3: Showing penile lymphoedema stenosis was noted with a pressure gradient of $28.2 \mathrm{~mm} \mathrm{Hg}$. USG of whole abdomen and scrotum was reported as mild hepatosplenomegaly, undescended right testis, and bilateral scrotal oedema. ICT for filaria was negative.

Our patient was diagnosed as a case of definite Noonan syndrome because he has typical facial features plus 3 more major criteria i.e. pulmonary stenosis, height $<3^{\text {rd }}$ percentile, pectus carinatum and 1 more minor criteria i.e. cryptorchidism and lymphatic dysplasia. DNA studies could not be done because of lack of facilities. His family members were examined but none of them had any major or minor features of Noonan syndrome.

He and his family were counseled about the disease. Orchidopexy was done in the Department of Paediatric Surgery of RMCH. Lymphoedema of his limb was not causing much trouble, but because of penile lymphoedema, he was referred to a plastic surgeon. His pulmonary stenosis was mild and did not warrant any intervention.

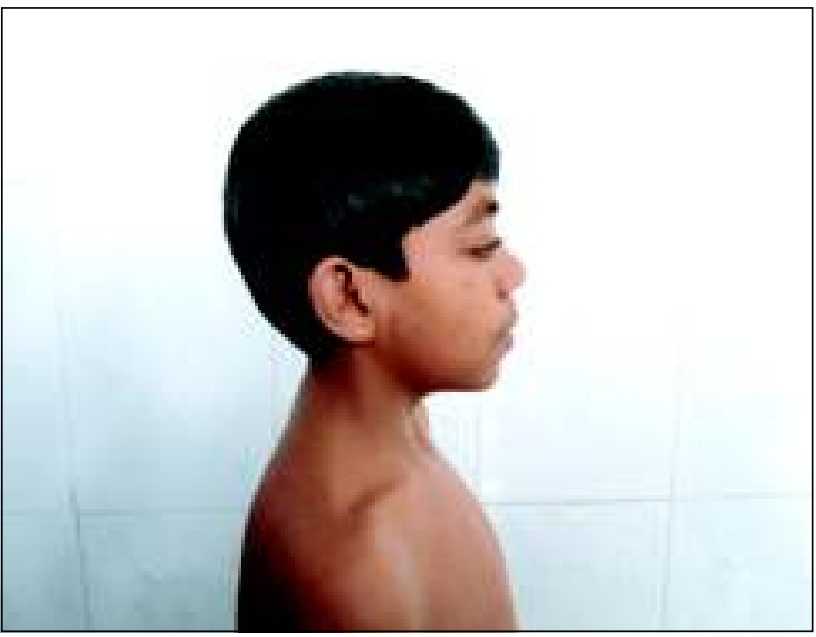

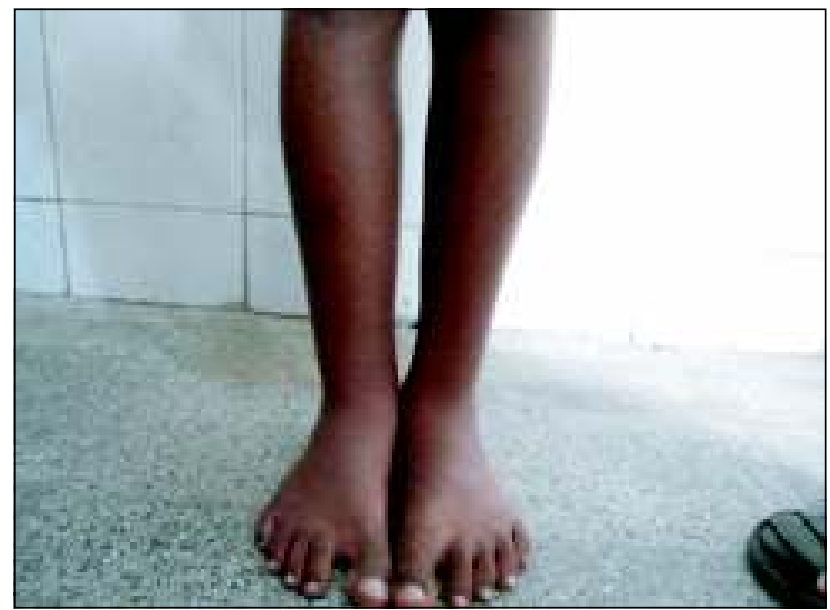

Fig.-4: Showing lymphoedema of right lower limb 


\section{Discussion:}

Primary lymphoedema is classified into 3 subtypes: congenital lymphoedema (Milroy disease) appearing between 0-2 years of age; lymphoedema precox appearing between 235 years of age and lymphoedema tarda appearing after 35 years of age. Our patient presented with lymphoedema precox; characteristic facial and other features were noted during evaluation of the underlying cause. Since the first reports on the NS, it was noticed that lymphoedema is one of the cutaneous manifestations of this condition. Lymphatic vessel dysplasia, hypoplasia, or aplasia is observed in $20 \%$ of patients with NS. They lead to generalized lymphoedema, peripheral lymphoedema, pulmonary lymphangiectasia or intestinal lymphangiectasia. ${ }^{8}$ Lymphangiographic studies have indicated that obstructed lymphatic drainage caused by congenital hypoplasia or absence of superficial lymphatic channels is a factor in the production of oedema in these patients. ${ }^{9}$ The most common manifestation of the lymphatic dysplasia is dorsal limb lymphoedema, which generally disappears during childhood. In our case, this did not happen; his lymphoedema of penis and lower limb is still persisting. ${ }^{10}$ It is possible that variation in phenotypic expression among different patients with is not only the result of heterogeneity but may also represent variability. Variation in timing of appearance and resolution of edema at different stages of development, the anatomical site of involvement, and the severity of edema may all modify the phenotype. For example, early onset lymphatic obstruction prior to complete organogenesis might result in more global effects and a more severe phenotype, whereas late obstruction may be manifest in a milder phenotype. Similarly, lymphatic abnormalities that undergo early spontaneous in-utero resolution may produce a milder phenotype. Involvement of peripheral lymphatics should lead to edema limited to the limbs, whereas a generalized lymphatic dysplasia would result in a more widespread process and, perhaps, a more severe phenotype. These differences might account for intrafamilial and interfamilial variability in the expression of NS. ${ }^{11}$

\section{Conclusion:}

Though filariasis is the commonest cause of lymphoedema in our country, Noonan syndrome should also be considered in the differential diagnosis, especially if the face appears dysmorphic.

\section{Conflict of Interest : None}

\section{References:}

1. Jacqueline A. Noonan. Amer J Dis Child. October 1968, Volume $116: 373-380$

2. Kobylinski 0. Ueber eine flughautah nliche Ausbreitung am Haise. Arch Anthropol 1883;14:342-8

3. Nora JJ, Fraser FC. Medical genetics: principles and practice. 2nd ed. Philadelphia: Lea and Febiger, 1981

4. Allanson JE. Noonan syndrome. J Med Genet 1987; 24(1): 9-13

5. Tartaglia M, Gelb BD. Noonan syndrome and related disorders: genetics and pathogenesis. Annu Rev Genomics Hum Genet 2005; 6:45-68

6. Nystrom A-M, Ekvall S, Berglund E, Bjorkqvist M, Braathen . J Med Genet 2008;45:500-506

7. Van der Burgt I, Berends E, Lommen E, van Beersum S, Hamel B, Mariman E. Clinical and molecular studies in a large Dutch family with Noonan syndrome. Am J Med Genet. 1994;53:187-191

8. Ineke van der Burgt. Noonan syndrome. Orphanet J Rare Dis. 2007; 2: 4. Published online 2007 January 14. doi: $10.1186 / 1750-1172-2-4$

9. Miller M, Motulsky A. Noonan syndrome in an adult family presenting with chronic lymphedema. Am J Med 1978; 65:379-383

10. Mendez H MM, Opitz J M. Noonan Syndrome: A Review. American Journal of Medical Genetics 1985, 21:493-506

11. Witt, D. R., McGillivray, B. C., Allanson, J. E., Hughes, H. E., Hathaway, W. E., Zipursky, A., Hall, J. G. Bleeding diathesis in Noonan syndrome: a common association. Am. J. Med. Genet. 31: 305-317, 1988 